
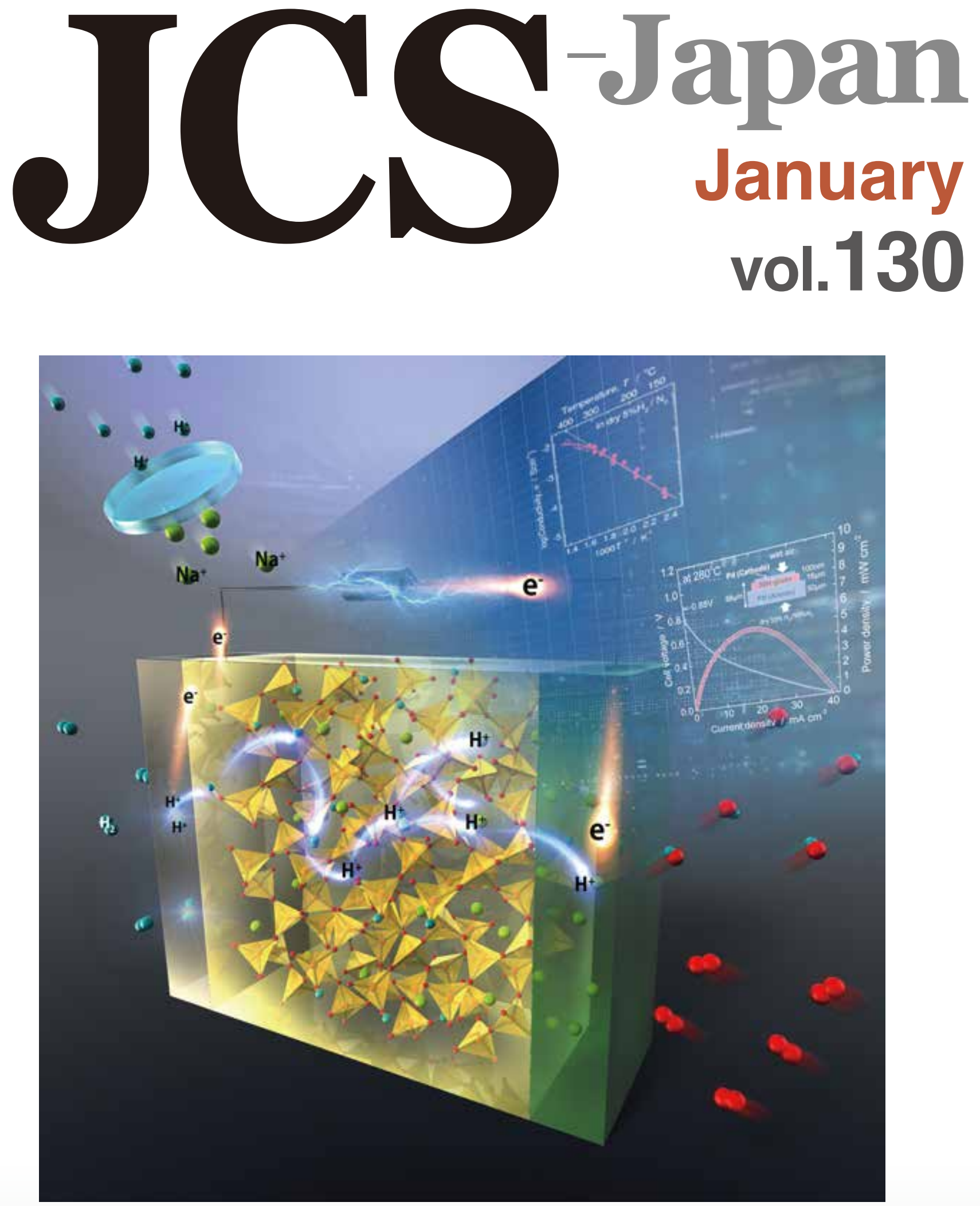

Journal of the Ceramic Society of Japan 


\title{
Proton-conducting phosphate glass: Recent development as an electrolyte in intermediate temperature fuel cells
}

\author{
Tomohiro ISHIYAMA ${ }^{1, \dagger}$, Takuya YAMAGUCHI ${ }^{1}$ and Takahisa OMATA $^{2}$ \\ ${ }^{1}$ Research Institute for Energy Conservation, Department of Energy and Environment, National Institute \\ of Advanced Industrial Science and Technology (AIST), 1-1-1 Higashi, Tsukuba, Ibaraki 305-8565, Japan \\ ${ }^{2}$ Institute of Multidisciplinary Research for Advanced Materials, Tohoku University, 2-1-1 Katahira, Sendai 980-8577, Japan
}

\begin{abstract}
Recently, it has been reported that phosphate glasses with high proton conductivity in the intermediate temperature range have been successfully developed using a proton carrier injection technique with a high concentration for electrochemical ion substitution. In this review, we summarize the characteristics of the bonding states between protons and oxygen in phosphates and the concepts of material design for achieving high proton conductivity in phosphate materials. This paper introduces a carrier proton injection technique called the alkaliproton substitution (APS) method, which was developed as a process for increasing the concentration of proton carriers and required a breakthrough in the conventional approach to the development of phosphate-glass-based proton conductors. Additionally, the knowledge obtained regarding the correlations between glass components, glass structure, and proton mobility is summarized. This paper also describes the characteristics of protonconductive phosphate glasses prepared using the APS method, demonstrating that they have the unique property of being able to carry only protons as charge carriers in any atmosphere. In conclusion, future strategies for improving proton conductivity and the potential for developing new applications are discussed. @2022 The Ceramic Society of Japan. All rights reserved.
\end{abstract}

Key-words : Phosphate glass, O-H bond, Alkali-proton substitution, Proton conductivity, Fuel cell

\section{Proton conduction of oxoacids and their salts}

Hydrogen in oxoacids such as phosphoric acid and sulfuric acid exhibits high proton conductivity based on strong hydrogen bonding. By utilizing this property, phosphoric acid (anhydrous $\mathrm{H}_{3} \mathrm{PO}_{4}$ or concentrated $\mathrm{H}_{3} \mathrm{PO}_{4}$ solution) has been used as an electrolyte in phosphoric acid fuel cells (FCs). ${ }^{1), 2)}$ However, liquid electrolytes are not able to retain their shape based on their liquid nature, so it is difficult to use them alone and their evaporation is a known issue. As solid electrolyte materials based on phosphates, many studies have reported the use of inorganic solid acids such as $\mathrm{CsH}_{2} \mathrm{PO}_{4}$ and phosphate glasses. ${ }^{3)-6)}$

$\mathrm{CsH}_{2} \mathrm{PO}_{4}$-based materials do not have high proton conductivity at low temperatures, but their proton conductivity increases significantly when a phase transition occurs at $228^{\circ} \mathrm{C}$ or higher to a structure that allows the rotational motion of protons, which is called the superprotonconductive phase. Because this structural phase transition is accompanied by a large volume change, a lack of

$\dagger$ Corresponding author: T. Ishiyama; E-mail: tomohiro. ishiyama@aist.go.jp

* Preface for this article: Dol http://doi.org/10.2109/jcersj2. 130.P1-1 mechanical stability during repeated thermal cycling is a difficult issue. Additionally, the long-term stability of proton conductivity is problematic because it is necessary to maintain a high humidification state to maintain proton conductivity in the temperature range at which proton conductivity is high.

Among the crystalline materials that differ from phosphates, but have the most potential for use in various devices, $\mathrm{BaZrO}_{3}$-based acceptor-doped perovskite proton conductors are recognized as promising materials. ${ }^{7)-10)}$ In these materials, it is still important to improve the proton transport number and proton conductivity. ${ }^{11)-14)}$ To improve proton conductivity, it is possible to control doping materials and their amounts to adjust the local structures and concentrations of protons. However, in crystalline materials, the allowable range of composition changes is relatively narrow. In contrast, for glass materials, a wide range of compositional tuning for controlling proton mobility can be considered. Additionally, because glass has the property of softening, it can be easily thinned, which is difficult to achieve with crystalline materials. Thinning has the advantage of reducing the resistance of proton conduction in various devices.

The proton conductivity of phosphate glasses was first reported by Namikawa et al. in 1966. ${ }^{15}$ ) In the early days following the discovery of proton conductivity in 
phosphate glasses, there were some scholars who denied the discovery, saying that protons could not be conducted in glass. However, proton conductivity in glass became widely recognized when it was clarified that proton conduction originates from $\mathrm{O}-\mathrm{H}$ groups that remain in trace amounts in glass structures. ${ }^{16)}$ Additionally, Abe et al. found that the high proton conductivity in phosphate glasses can be attributed to the fact that protons in phosphate glasses form much stronger hydrogen bonds than those in silicate glasses. ${ }^{17-23)}$ To achieve high proton conductivity by increasing the proton concentration in phosphate glasses, which have high proton mobility, one can melt the glass at a low temperature and leave a large amount of water in the structure. ${ }^{24), 25)}$ Although some improvement in proton conductivity has been observed after applying this method, the residual water molecules are not anchored in the structure and do not form $\mathrm{O}-\mathrm{H}$ bonds with the oxygen in the framework structure, so they are gradually dehydrated and lost in the temperature range at which proton conduction is exhibited, making it difficult to maintain the proton conductivity of the material. Additionally, because the glass structure is not sufficiently dehydrated and polymerized, it has poor chemical durability and is not suitable for practical use. To overcome these issues, we succeeded in developing a novel proton conductor by using an electrochemical proton injection process called the alkali-proton substitution (APS) method, ${ }^{26), 27)}$ which is described in detail later, as a method for adding a large amount of protons in the form of $\mathrm{O}-\mathrm{H}$ groups anchored in the glass structure to ensure stability in the operating temperature range. Proton-conducting phosphate glasses prepared using the APS method have high chemical stability because they utilize conduction by protons bound to a strong glass structure. Additionally, they have a protonconducting mechanism that does not originate from the water component and has the unique property of being able to exhibit proton conductivity in a dry atmosphere, ${ }^{28), 29)}$ which is not possible with conventional proton-conducting materials. In electrochemical devices, the stability of proton conductivity in a dry environment with a high operating temperature is crucial for realizing high performance by reducing electrode overvoltage and the use of platinum-free electrocatalysts, which has emerged as the most promising direction for polymer electrolyte FCs development in recent years. ${ }^{30)}$ The APS method makes it possible to inject protons into the glass structure at a concentration 100 times greater than that of protons in phosphate glasses prepared through conventional high-temperature melt-quenching processes. We have developed a glass material that exhibits a proton conductivity of $2 \times 10^{-3} \mathrm{~S} \mathrm{~cm}^{-1}$ with a proton transport number of one at $300^{\circ} \mathrm{C}^{29)}$ In the following sections, after describing the origins of weakened $\mathrm{O}-\mathrm{H}$ bond, which is important for understanding the proton conductivity of phosphate glasses, the features of the process of increasing the proton carrier concentration and designing the glass structure, which require a breakthrough in the conventional approach to the development of proton conductors in phosphate glasses, are summarized.

\section{2. $\mathrm{O}-\mathrm{H}$ bond strength in phosphate glass}

The protons in oxides are strongly bound to the oxygen in the structure and must migrate by hopping to neighboring oxygen atoms for conduction. The ease of detrapping is determined by the strength of the bonds between the oxygen and protons, namely the $\mathrm{O}-\mathrm{H}$ bond strength. The ease of migration depends largely on structural factors such as the size of the diffusion path space and distance to neighboring sites. The $\mathrm{O}-\mathrm{H}$ bond strength is approximately determined by the electron density of the oxygen to which a proton binds and the hydrogen bond strength with the oxygen located on the other side of the binding oxygen. The characteristics of $\mathrm{O}-\mathrm{H}$ bond strength in phosphoric acid and phosphate glass are described in terms of electron density. Phosphates form a structure with $\mathrm{PO}_{4}$ as the base unit, which consisting of four $\mathrm{O}$ atoms coordinated to $\mathrm{P}$ according to Pauling's first law, which determines the coordination number according to the ionic radius ratio. Because phosphorus is a pentavalent cation, at least one oxygen atom must form a double bond with phosphorus when considering only the number of charges. However, because the double-bond structure is not a resonance structure and is unstable in terms of energy levels, it is stabilized by transforming into a resonance structure in which the electrons involved in the double bond are shared with another oxygen. In this case, the electron density of the oxygen increases and the covalency of the $\mathrm{P}-\mathrm{O}$ bond becomes stronger. Since maintaining this bonding state is a stable structure, the bond between the proton and oxygen is relatively weak covalent and exists as a proton with weak $\mathrm{O}-\mathrm{H}$ bonding strength. In the case of silicates, a structure with $\mathrm{SiO}_{4}$ as the basic unit is also formed, but in this case, because four oxygen species are coordinated with the tetravalent cation $\mathrm{Si}$, the electron density of the oxygen is equivalent to that of the four oxygen species, which is stable, and no deviation in the electron density occurs. Therefore, the covalency of the $\mathrm{Si}-\mathrm{O}$ bond is weaker than that of the $\mathrm{P}-\mathrm{O}$ bond. Furthermore, when a proton binds to the oxygen of $\mathrm{Si}-\mathrm{O}$, a more strongly covalent $\mathrm{O}-\mathrm{H}$ bond is formed compared to the case of binding to $\mathrm{P}-\mathrm{O}$. The difference in the center element, $\mathrm{M}$, of the oxoate causes a difference in the degree of covalency between the $\mathrm{M}$ and $\mathrm{O}$ bonds. As a result, in the case of phosphates, the covalency of a proton bound to $\mathrm{P}-\mathrm{O}$ is weakened, allowing the proton to exist in a weakly bound state.

Phosphate glasses have non-bridging oxygen without the addition of glass modifiers because there is at least one non-bridging oxygen per $\mathrm{PO}_{4}$ unit because up to three oxygens of the $\mathrm{PO}_{4}$ tetrahedra are used for network formation, as shown in Fig. 1(a). Additionally, based on the high ionic connectivity of the non-bridging oxygen, a wide range of hydrogen bonds are formed. In the case of silicate glasses, protons are strongly bound to oxygen. Because non-bridging oxygen is not produced without modifier components, as shown in Fig. 1(b), and because the distance over which hydrogen bonds can be formed is short 
(a)

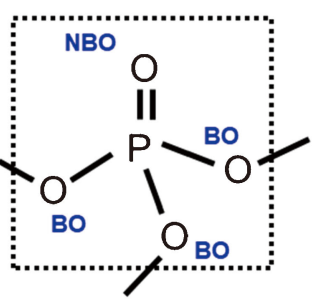

Fig. 1. (a) $\mathrm{PO}_{4}$ unit structure in $\mathrm{P}_{2} \mathrm{O}_{5}$ and (b) $\mathrm{SiO}_{4}$ unit structure in $\mathrm{SiO}_{2}$. $\mathrm{BO}$ and $\mathrm{NBO}$ in the figure represent bridging and nonbridging oxygen, respectively.

Table 1. XPS peak positions of $\mathrm{O} 1 \mathrm{~s}$ in silicate and phosphate glasses

\begin{tabular}{ccc}
\hline Glass & $\mathrm{O}$ 1s binding energy/eV & Ref. \\
\hline $\mathrm{P}_{2} \mathrm{O}_{5}$ glass & $530-536$ & 34 \\
$\mathrm{SiO}_{2}$ glass & $532-534$ & 32,35 \\
Sodium silicate glass & $529-533$ & 32 \\
Sodium phosphate glass & $534-540$ & 34 \\
\hline
\end{tabular}

based on the low ionic bonding properties of non-bridging oxygen, protons are present in the glass structure with much less mobility than protons in phosphate glasses. As mentioned above, phosphate is a material that can be expected to have high proton conductivity based on the high mobility of protons because the binding of protons by oxygen is weak and the formation of hydrogen bonds is easy.

The electron densities of oxygen can be observed by X-ray photoelectron spectroscopy (XPS) and differences in proton binding states can be observed by infrared absorption spectroscopy and nuclear magnetic resonance (NMR) analysis. Evidence of the high electron density of oxygen in phosphate glasses is provided by the XPS peak position of the $\mathrm{O} 1 \mathrm{~s}$ orbital (Table 1). ${ }^{31)-35)}$ As described earlier, compared to the $\mathrm{O} 1 \mathrm{~s}$ peak in silicate glasses, which form strong $\mathrm{OH}$ bonds with oxygen, the peak shift to the highenergy side in phosphate glasses indicates a greater oxygen electron density. In the Fourier transform infrared (FTIR) spectrum, the absorption peak position of the $\mathrm{O}-\mathrm{H}$ group corresponds to the $\mathrm{O}-\mathrm{H}$ bond strength. The greater the $\mathrm{O}-\mathrm{H}$ bond strength, the greater the absorption at higher wavenumbers. The $\mathrm{OH}$ absorption peak of silicate glasses such as soda lime aluminosilicate appears at $3500 \mathrm{~cm}^{-1}$, as shown in Fig. 2(a), ${ }^{36)-38)}$ and the full width at half maximum of the peak is approximately $200 \mathrm{~cm}^{-1}$. In contrast, the $\mathrm{OH}$ absorption peak position of phosphate glasses appears at $2800 \mathrm{~cm}^{-1}$ and its half width is approximately 700 $\mathrm{cm}^{-1}$, as shown in Fig. 2(b). ${ }^{16), 21), 39)}$ In silicate glasses, the $\mathrm{O}-\mathrm{H}$ bond strength distribution is narrow based on strong binding to oxygen, but in phosphate glasses, $\mathrm{O}-\mathrm{H}$ bond strength is reduced and protons form hydrogen bonds with non-bridging oxygen at various distances in the glass structure, resulting in a broad distribution of $\mathrm{O}-\mathrm{H}$ bond strength. It is known that the strength of hydrogen bonding corresponds to the $\mathrm{O}-\mathrm{H}$... $\mathrm{O}$ distance between $\mathrm{O}$ and $\mathrm{H}$, and the oxygen that forms the hydrogen bond, and that the

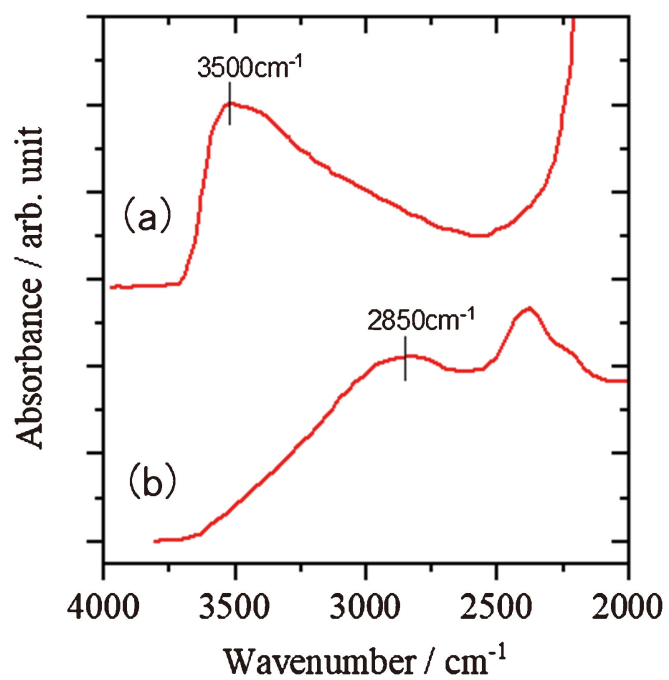

Fig. 2. FTIR spectra in the $\mathrm{O}-\mathrm{H}$ regions of (a) $52.1 \mathrm{SiO}_{2}-$ $17.4 \mathrm{Al}_{2} \mathrm{O}_{3}-11.7 \mathrm{CaO}-18.8 \mathrm{Na}_{2} \mathrm{O}^{36}$ and (b) $45 \mathrm{BaO}-55 \mathrm{P}_{2} \mathrm{O}_{5}$ glasses. ${ }^{39)}$ The absorbance was normalized for comparison.

distance is shorter when the hydrogen bonding strength is higher. ${ }^{40-42)}$ This indicates that the hydrogen bond strength is modulated by the change in the O-H...O distance in the glass structure, which is one of the parameters for designing an optimal glass structure.

Some phosphate-based materials have been reported to possess relatively high proton conductivity based on molecular water-originated proton conduction, but this does not take advantage of the weak $\mathrm{O}-\mathrm{H}$ bond features of phosphates mentioned earlier. ${ }^{24), 43)}$ Instead, this advantage is mainly attributed to the increase in proton concentration caused by the formation of water molecules in liquid form. It is necessary to clearly recognize this difference to gain an accurate understanding of the proton conductivity of phosphate materials. As mentioned earlier, protons exist in phosphate glasses with weakened $\mathrm{O}-\mathrm{H}$ bonds because strong hydrogen bonds also form in phosphate glasses. It is known that hydrogen bonds are formed in liquid water molecules, but as observed in the FTIR spectrum of water, ${ }^{44)}$ the hydrogen bond strength is not as great as that in phosphate glasses. In the case of low-temperature molten glasses ${ }^{24), 25)}$ and pyrophosphate materials using the surface hydration phase ${ }^{45)}$ described in Section 1 , the FTIR spectra of these materials clearly indicate that they are mainly composed of protons with hydrogen bonding strength in the same range as that of water in the highwavenumber region. In other words, the proton conductivity of these materials is based on water-derived proton conduction, which is different from proton conduction based on hydrogen bonds in the structure. Care should be taken to understand this difference and avoid confusion. It has been demonstrated that the only way to achieve high proton conductivity with practical stability in phosphateglass-based materials is to use protons in the glass structure, rather than protons derived from water. In the next section, details regarding glass structure design methods, including the electronic states of oxygen and methods for 
increasing the concentration of protons that form strong hydrogen bonds in a glass structure, are discussed.

\section{Material processing to enhance proton conductivity}

As described in Sections 1 and 2, to obtain a material that stably maintains protons in its structure and exhibits high proton conductivity, it is necessary to increase the concentration of protons in the form of $\mathrm{O}-\mathrm{H}$ groups anchored in the structure. Various methods for increasing the concentration of protons in materials have been investigated, including the dissolution of water into oxygen vacancies formed by adding acceptors ${ }^{7), 9)}$ and the ion exchange method in aqueous solutions. ${ }^{46), 47)}$ In the case of perovskite-type oxides such as $\mathrm{BaZrO}_{3}$ and $\mathrm{SrZrO}_{3}$, the oxygen vacancies formed by substituting some of the Bsite ions with trivalent ions are used to dissolve protons according to the defect equilibrium defined in the following equations and Fig. 3:

$$
\begin{aligned}
& \mathrm{Y}_{2} \mathrm{O}_{3} \rightarrow 2 \mathrm{Y}_{\mathrm{Zr}}^{\prime}+3 \mathrm{O}_{\mathrm{O}}^{\times}+\mathrm{V}_{\mathrm{O}}^{\bullet \bullet} \\
& \mathrm{H}_{2} \mathrm{O}+\mathrm{V}_{\mathrm{O}}^{\bullet \bullet}+\mathrm{O}_{\mathrm{O}}^{\times} \rightleftarrows 2 \mathrm{OH}_{\mathrm{O}}^{\bullet}
\end{aligned}
$$

The only way to increase the concentration of proton dissolution in this mechanism is to increase the concentration of doping elements, but there is a limit to increasing the concentration because introducing defects at high concentrations leads to defect aggregation. Proton injection as a major component of the structure is necessary and proton injection by ion exchange is a promising candidate solution. An aqueous-solution-based ion-exchange method has been reported in which a beta-alumina material is dipped into a concentrated sulfuric acid solution and sodium ions are exchanged for hydronium ions, resulting in the dissolution of the protons in the crystal. ${ }^{46)}$ In this form, the protons cannot dissolve into the structure as $\mathrm{O}-\mathrm{H}$ groups, but exist as hydronium ions derived from water, which are dehydrated when heated, resulting in poor thermal stability. Therefore, it is necessary to increase the concentration of protons as $\mathrm{O}-\mathrm{H}$ groups, rather than as water molecules, to achieve a strong framework structure.

To solve these problems, an APS method was developed to inject protons from hydrogen gas directly instead of using water-derived protons, where ion exchange is conducted using an electrochemical reaction by applying a voltage in a high-temperature hydrogen atmosphere, as shown in Fig. 4. ${ }^{27), 48)}$

When this method was applied to a NASICON crystal material, ${ }^{49)}$ protons could be injected through exchanges

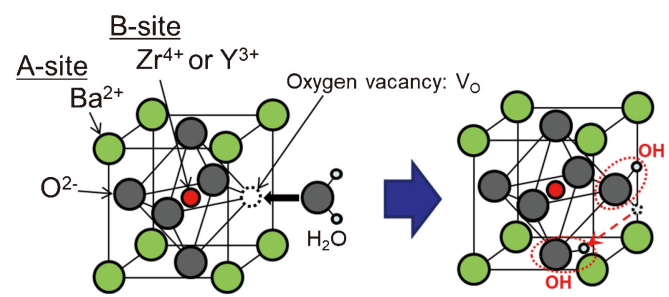

Fig. 3. Schematic illustration of the proton incorporation reaction in acceptor-doped perovskite-type oxides. with sodium ions, but the crystal became amorphous. In the ion-exchange treatment method for crystalline materials, the ionic radius difference between alkali ions and protons is too large, which causes compressive stress to be applied and the crystal structure to be broken. As a result, mechanical destruction of the crystal grains also occurs and ion exchange cannot be completed over the entire material. In contrast, because the glass material is a structure in a liquid or supercooled liquid state, the stress caused by the ionic radius difference can be relaxed by deformation. As a result of applying the APS to phosphate glass, the ion substitution process can be completed effectively depending on the operating conditions and a large number of protons can be successfully injected. ${ }^{26)}$ The APS method is described below.

In the APS method, mobile alkali ions in a material are removed and replaced with protons by applying a voltage, so the process is conducted in a temperature range in which the conductivity of alkali ions is sufficient and in a hightemperature atmosphere containing hydrogen because proton uptake from the anode side is necessary. By using Pd as an anode, the oxidation reaction of hydrogen into protons occurs smoothly and the protons are incorporated into the glass to fill the vacancies formed by the migration of alkali ions. When continuing the current flow, the alkali ions are substituted into protons from the anode side to the cathode side of the glass. The use of molten tin as a cathode enables a smooth substitution process by dissolving the alkali metals discharged by the electrochemical reduction reaction. By directly replacing the alkali ions, which are monovalent cations, with protons, it is possible to inject protons in a form that does not contain water molecules. Because the substitution process is conducted at a high temperature above the glass transition temperature, the internal stress caused by the ionic radius difference is released by the liquid nature of the glass melt. Because materials with alkali ion conductivity are sufficient for applying the APS method, glasses with alkali ion conductivity prepared using the conventional high-temperature melt-quenching method can be used. Although the APS treatment causes some structural changes as a result of structural relaxation, these changes are not as significant as the collapse of the framework structure of the glass. Therefore, it is possible to fabricate highly proton-conductive glasses with a strong framework structure and large number of protons, which is

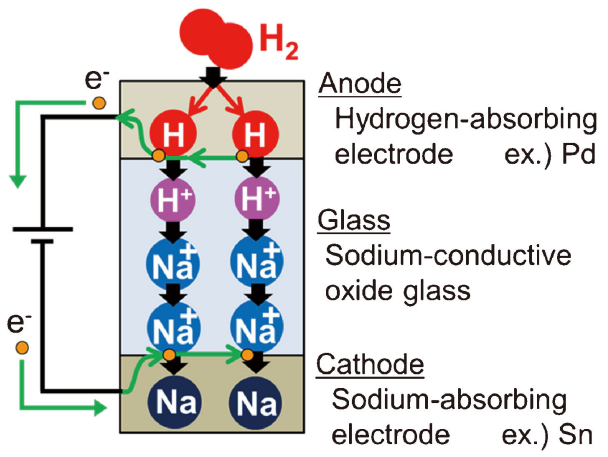

Fig. 4. Schematic illustration of the APS process. ${ }^{48)}$ 
not possible to obtain using the traditional method based on the tradeoff relationships discussed above.

\section{Composition and structure for enhancing proton mobility}

Because the APS process is conducted in a hightemperature hydrogen atmosphere, in the case of transition metals such as tungsten, conduction electrons are generated in the glass when it is reduced by hydrogen or electrochemical reactions. ${ }^{27), 48)}$ When electron conductivity is exhibited, the proton transport number required for protonconducting electrolytes is not one. Therefore, care must be taken regarding the concentration of transition metal components.

Proton mobility, which governs proton conductivity, is determined by the $\mathrm{P}-\mathrm{O}$ bond strength and hydrogen bond strength, which are mainly determined by the glass structure before APS treatment. The glass structure before APS treatment can be modified by tailoring the composition of the glass used in the high-temperature melt-quenching process. In other words, it is possible to study the effects of various glass compositions and structures on proton conductivity. To achieve high proton conductivity, it is necessary to understand the effects of glass framework components and network structures on proton mobility separately. The following discussion summarizes the findings obtained in our research thus far. ${ }^{29), 33), 50)-58)}$ From the perspective of structure and bonding states, the correlation between the glass structure and barriers to proton dissociation from the bound position and migration to neighboring sites has been clarified by using a glass in which only protons are carriers. To understand the effects of glass components on the strength of $\mathrm{P}-\mathrm{O}$ bonds, which dominate the strength of the $\mathrm{O}-\mathrm{H}$ bonds determining the ease of dissociation from bond positions, the proton mobility and electronic state of oxygen were investigated in the presence of the alkaline earth metals $\mathrm{Ba}$ an $\mathrm{Mg} .{ }^{33)}$ In glass with a composition of $35 \mathrm{NaO}_{1 / 2}-5 \mathrm{RO}-3 \mathrm{NbO}_{5 / 2}-3 \mathrm{LaO}_{3 / 2}-$ $2 \mathrm{GeO}_{2}-2 \mathrm{BO}_{3 / 2}-50 \mathrm{PO}_{5 / 2}$ ( $\mathrm{R}: \mathrm{Mg}$ and $\mathrm{Ba}$ ), the proton mobility was higher with $\mathrm{Ba}$ than with $\mathrm{Mg}$. Specifically, the $\mathrm{P}-\mathrm{O}$ bonds became more covalent in the Ba containing glass because $\mathrm{Ba}$ formed stronger ionic bonds with the non-bridging oxygen in $\mathrm{PO}_{4}$ units. The protons bonded to the $\mathrm{P}-\mathrm{O}$ formed $\mathrm{O}-\mathrm{H}$ bonds with higher ionic bonding properties. As a result, the $\mathrm{O}-\mathrm{H}$ bonds were weakened and proton mobility increased. Regarding the binding state of the protons, as reported by Abe et al., the protons bound to the terminal structure $\mathrm{Q}^{1}$ unit of the $\mathrm{PO}_{4}$ chain structure have weakened hydrogen bond strength, as shown in Fig. 5. ${ }^{17)}$ Therefore, as the number of $Q^{1}$ units increases, the concentration of protons with stronger $\mathrm{O}-\mathrm{H}$ bonds (i.e., with a higher activation energy for conduction) will increase. $^{23)}$

Based on this finding alone, it seems desirable for the glass structure to form a polyphosphate structure with a high degree of polymerization that contains as few $\mathrm{Q}^{1}$ unit structures as possible. When $\mathrm{Y}, \mathrm{Al}$, etc. are added to glass with a composition of $35 \mathrm{NaO}_{1 / 2}-1 \mathrm{WO}_{3}-8 \mathrm{NbO}_{5 / 2}-$

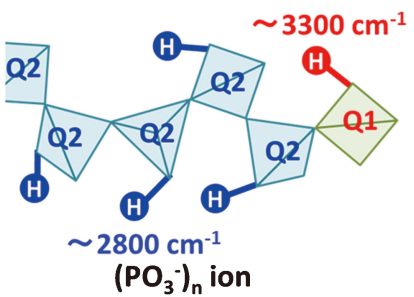

Fig. 5. Schematic illustration of the glass chain structure of phosphate glass. $\mathrm{Q}^{1}$ indicates the $\mathrm{PO}_{4}$ units on the edge of the chain structure.

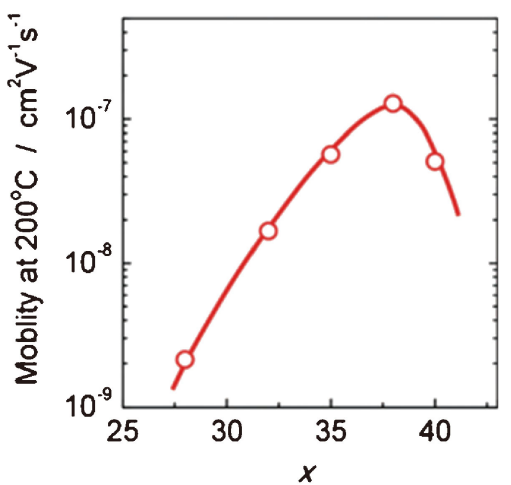

Fig. 6. Proton mobility at $200^{\circ} \mathrm{C}$ for glasses after applying the APS method as a function of $x$ in $x \mathrm{NaO}_{1 / 2}-1 \mathrm{WO}_{3}-8 \mathrm{NbO}_{5 / 2}-$ $5 \mathrm{LaO}_{3 / 2}-(86-x) \mathrm{PO}_{5 / 2}{ }^{55)}$ (reproduced from Ref. 55 with permission from the PCCP Owner Societies).

$5 \mathrm{LaO}_{3 / 2}-51 \mathrm{PO}_{5 / 2}$, which does not have a high degree of polymerization with an $\mathrm{O} / \mathrm{P}$ ratio of 3.44 , the $\mathrm{PO}_{4}$ unit $\left[\mathrm{Q}^{1}(\mathrm{M})\right]$, which is similar to the $\mathrm{Q}^{1}$ structure, is increased by $\mathrm{Y}$ and $\mathrm{Al}$ interrupting the $\mathrm{PO}_{4}$ chain structure. ${ }^{52), 54)}$ This leads to an increase in the concentration of protons with strong $\mathrm{P}-\mathrm{O}-\mathrm{H}$ bond strengths and the proton mobility tends to decrease. This is a result of the increase in the proton concentration, which requires a high dissociation energy for proton conduction. The structural dependence of the diffusion barrier has been investigated as another major factor determining proton mobility and the following findings have been obtained. The dependence of the proton mobility on the degree of polymerization was investigated when the $\mathrm{O} / \mathrm{P}$ ratio increased from 3.27 to 3.60 ( $x=$ $28,32,35,38$, and 40) in glasses with a composition of $x \mathrm{NaO}_{1 / 2}-1 \mathrm{WO}_{3}-8 \mathrm{NbO}_{5 / 2}-5 \mathrm{LaO}_{3 / 2}-(86-x) \mathrm{PO}_{5 / 2}$ before APS treatment. ${ }^{55)}$ Considering only the amount of $\mathrm{Q}^{1}$ units, proton mobility should increase as the degree of polymerization increases (i.e., $x$ decreases). However, as shown in Fig. 6, the proton mobility increases up to a composition of $x=38$ and then begins to decrease. This is likely because the contribution from the increase in the migration barrier is greater than the decrease in the number of $\mathrm{Q}^{1}$ units as a result of the narrowing of the proton diffusion path caused by the extension of the chain structure. Therefore, the charge balance between the components of the glass structure and the formation of the terminal substructure control the bonding between $\mathrm{P}-\mathrm{O}$ and protons, whereas the length of the chain structure controls the ener- 
gy barrier during proton transfer. Therefore, it is necessary to design a structure and composition that considers at least two factors that control dissociation and migration. Lowering the migration barrier is associated with lowering the thermal stability of the structure, which in turn reduces the glass transition temperature. Conversely, depending on structural control, it may be possible to adjust the temperature range in which proton conductivity can be exhibited.

\section{Proton conductivity of recent glasses}

In this section, we discuss the proton-conducting mechanisms and proton-conducting properties of protonconducting glasses developed based on the compositional design guidelines described in the previous sections. By using the APS method, we succeeded in increasing the concentration of protons anchored as $\mathrm{P}-\mathrm{O}-\mathrm{H}$ in a glass structure to as high as $10^{22} \mathrm{~cm}^{-3}$. Because the mobile ions in the glass were replaced by protons from sodium ions, the charge carriers in the glass fabricated using the APS are only protons if they do not contain conduction electrons stemming from transition metals. This conclusion was clearly supported by electromotive force measurements of the hydrogen concentration, water vapor concentration, and oxygen concentration cells, where the proton transport number was one. ${ }^{28)}$ The proton transport number was also confirmed to be one from the hydrogen production estimated from the current value during hydrogen pump operation, indicating that only protons can be transported under actual operating conditions. It was confirmed that the proton transport number was one, even when dry hydrogen was used, indicating that the proton conductivity was not derived from water and that the fabricated proton conductor can be used without humidification, unlike conventional proton conductors.

In the case of proton conductors such as the $\mathrm{BaZrO}_{3}$ conductor introduced in Section 3, the proton transport number, and proton and hole conductivities depend on the temperature and atmosphere (oxygen partial pressure, hydrogen partial pressure, water vapor partial pressure, etc.) in which they are used because the amount of dissolved protons, which are carriers, is determined by the defect equilibrium. This limits the scenarios in which they can be used in electrochemical device applications. In contrast, phosphate glasses prepared using the APS method depend on the dissolution mechanism of protons, which are carriers that are not related to the defect equilibrium and have the property that only protons can be carriers in any atmosphere. As shown in Fig. 7, because proton conductivity does not depend on oxygen partial pressure, these properties are considered to be reliable.

Although this property is unsurprising considering the mechanism of proton injection and conduction, it is very important for application to electrochemical devices. In fuel cell atmospheres, the use of $\mathrm{Pt}$ as a cathode and $\mathrm{Pd}$ for an anode yields a high proton transport number, as indicated by an open-circuit voltage (OCV) close to the theoretical value as shown in Fig. 8. This is a significant advantage in fuel cell applications because conventional

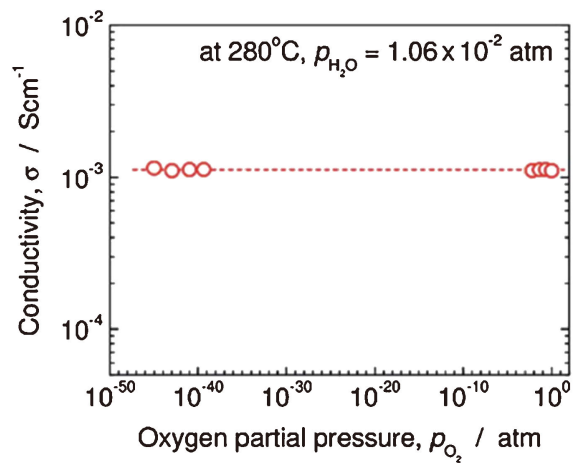

Fig. 7. Electrical conductivity of $36 \mathrm{HO}_{1 / 2}-4 \mathrm{NbO}_{5 / 2}-2 \mathrm{BaO}-$ $4 \mathrm{LaO}_{3 / 2}-4 \mathrm{GeO}_{2}-1 \mathrm{BO}_{3 / 2}-49 \mathrm{PO}_{5 / 2}$ glass at $280{ }^{\circ} \mathrm{C}$ as a function of $\mathrm{p}_{\mathrm{O} 2}$ (reproduced from Ref. 30 with permission from the Royal Society of Chemistry).

(a)

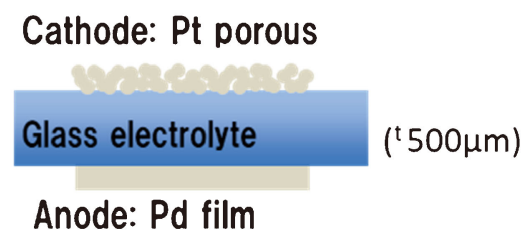

(b)

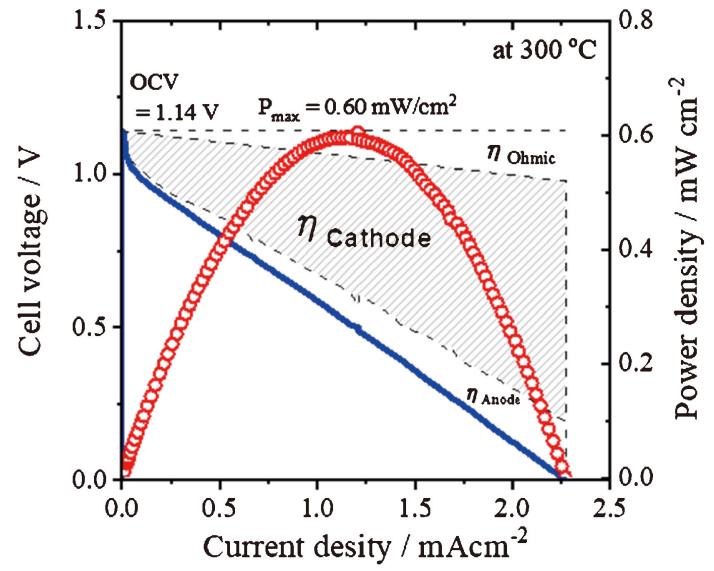

Fig. 8. Fuel cell performance with thick glass electrolyte. (a) and (b) shows the cell configuration and I-V performance with breakdown of overvoltage.

polymer-based electrolytes can only provide an OCV that is lower than the theoretical value based on the presence of fuel cross leakage.

A proton conductivity of $2 \times 10^{-3} \mathrm{~S} \mathrm{~cm}^{-1}$ at $300^{\circ} \mathrm{C}$ was achieved in a glass with a composition of $36 \mathrm{HO}_{1 / 2}-$ $4 \mathrm{NbO}_{5 / 2}-2 \mathrm{BaO}-4 \mathrm{LaO}_{3 / 2}-4 \mathrm{GeO}_{2}-1 \mathrm{BO}_{3 / 2}-49 \mathrm{PO}_{5 / 2},{ }^{30)}$ as shown in Fig. 9(a). It was confirmed that there was no significant decrease in proton conductivity over approximately $500 \mathrm{~h}$ in a dry hydrogen atmosphere at $280^{\circ} \mathrm{C}$, as shown in Fig. 9(b), indicating that there were no issues related to deprotonation, which is an issue with conventional proton conductors. The activation energy calculated from the Arrhenius plot of proton conductivity in the range 


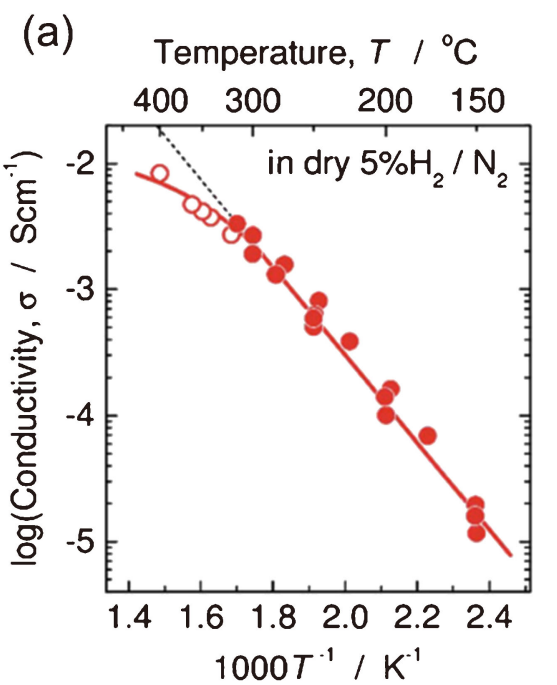

(b)

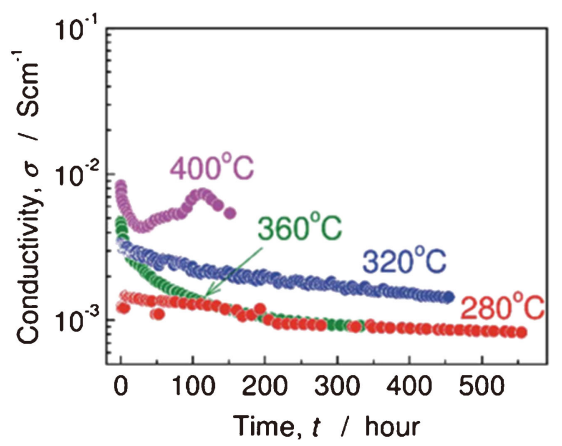

Fig. 9. (a) Proton conductivity of $36 \mathrm{HO}_{1 / 2}-4 \mathrm{NbO}_{5 / 2}-2 \mathrm{BaO}-$ $4 \mathrm{LaO}_{3 / 2}-4 \mathrm{GeO}_{2}-1 \mathrm{BO}_{3 / 2}-49 \mathrm{PO}_{5 / 2}$ glass and (b) time evolution of the proton conductivity of that glass at 280 to $400{ }^{\circ} \mathrm{C}^{29)}$ (reproduced from Ref. 30 with permission from the Royal Society of Chemistry).

of 150 to $300^{\circ} \mathrm{C}$ is in the range of 0.7 to $1.0 \mathrm{eV}$, which is similar to the value in conventional phosphate glasses, suggesting that the conduction mechanism is hopping conduction in the glass structure. In situ FTIR and NMR measurements suggest that the temperature dependence of the activation energy can be attributed to a slight weakening of the hydrogen bond strength caused by the expansion of the glass structure. ${ }^{59)}$

It is also important to know how to fabricate membrane electrode assemblies for use in FCs. Conventional solid oxide FCs and proton-conducting ceramic FCs require a high-temperature sintering process to form a dense electrolyte layer and there are technical challenges related to improving the sintering process to fabricate a thin electrolyte layer. In contrast, glass materials have no grain boundaries and can be easily formed by post-processing, such as hot rolling, which is a significant advantage for making electrolytes thinner. By taking advantage of the high thermal stability of protons in phosphate glasses prepared using the APS method, a thin electrolyte was successfully developed by hot pressing. Currently, the area resistance of proton conduction in electrolytes has been reduced to

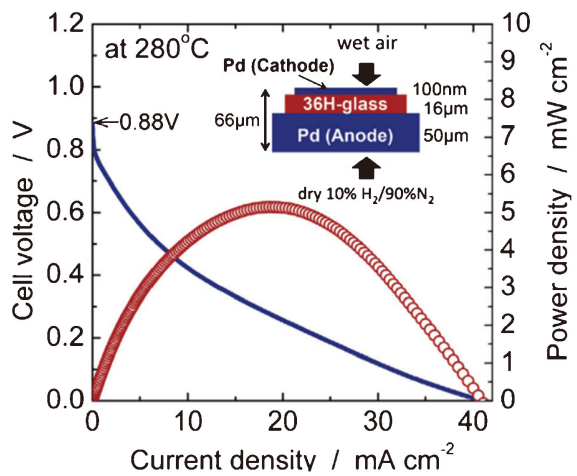

Fig. 10. Fuel cell performance with a thin $36 \mathrm{H}$ glass electrolyte. ${ }^{60)}$

$2.7 \Omega \mathrm{cm}^{2}$ by thinning the glass electrolyte to a thickness of $16 \mu \mathrm{m}$ on a $\mathrm{Pd}$ plate. It was confirmed that there was no change in the structure or proton conductivity of the glass after thinning, thus the thinning process could be completed without damaging the proton-conducting properties of the glass (proton transport number and proton conductivity). Although the OCV was low due to poor gas sealing, since the test setup was not optimized for thinfilm glass evaluation, a maximum power density of 5.6 $\mathrm{mW} \mathrm{cm}{ }^{-2}$ has been achieved in fuel cell operation, as shown in Fig. 10. ${ }^{60}$ Analysis using reference electrodes has revealed the occurrence of large over voltages at the cathode, and additional research is being conducted not only to improve electrolyte properties, but also to develop electrode materials to improve fuel cell performance. At present, we use thin-film dense electrodes, but since the electrode structure is not the conventional porous microstructure, we believe that the insufficient formation of the interface that serves as the reaction field is the cause of the large cathode overvoltage. A possible solution to these problems is to develop proton-electron mixed conducting materials to expand the reaction interface and provide a two-phase boundary reaction field in addition to the threephase boundary. As for the conventional electrode structure with a porous microstructure, the development of composite electrodes with the glass electrolyte itself, catalysts, and conductive materials is expected to improve the performance. Since these investigations have just begun, it is expected that this problem will be solved by constructing optimal electrode materials and structures.

\section{Summary and future challenges}

In this paper, the characteristics of phosphate materials, which favor proton conductivity among oxoates, were discussed. The deviation of the electron density on oxygen caused by the formation of $\mathrm{PO}_{4}$ tetrahedra is an important factor in the weakening of $\mathrm{O}-\mathrm{H}$ bonds and formation of hydrogen bonds. The incorporation of a large number of protons existing in the form of $\mathrm{O}-\mathrm{H}$, hydroxyl group, in the glass structure is one of the necessary factors to achieve high proton conductivity and it was discussed that such a state can only be achieved by using the method of APS into phosphate glasses. The high proton concentra- 
tion yielded by the APS method benefits the study of various relationships between glass structure and composition, and proton mobility, which is an effective process for acquiring insights into compositional design. Recently, the proton mobility at the glass transition temperatures of various glass compositions has been found to be in the range of $10^{-7}$ to $10^{-9} \mathrm{~cm}^{2} \mathrm{~V}^{-1} \mathrm{~s}^{-1}$. It is expected that proton conductivity can be improved to at least $7 \times 10^{-3} \mathrm{~S} \mathrm{~cm}^{-1}$ if the maximum proton mobility can be achieved at the highest proton concentration. ${ }^{57}$ The quantitative relationships between various components and proton mobility were revealed by using statistical methods based on material informatics ${ }^{50)}$ and experiments, ${ }^{61)}$ and further fine-tuning of composition will be promoted in the future. Regarding proton-conducting properties, proton-conducting glass prepared using the APS method is a material that can only use protons as carriers in any atmosphere and has the unique property of maintaining proton conductivity in a non-humidified atmosphere, which is not possible using conventional proton conductors. The development of FCs that take advantage of this feature is expected to expand the application of FCs technology because it can make conventional FCs systems significantly simpler without the need for humidification management. The development of electrode materials is the most important issue for future device development and one target is to develop proton-electron mixed conductive materials (MIEC) and composite methods using proton conductive materials and electrode materials. As mentioned in Section 3, it is possible to develop electronic conductivity in addition to proton conductivity by applying APS treatment to transitionmetal-containing glasses, which is expected to yield a new category of electrode materials through the development of MIEC materials. Such materials are also expected to be used in new technological fields, such as electrochemical proton supply to catalysts and reaction promotion via activity modulation, including electrosynthesis reactions based on reverse operation in FCs, which have attracted significant attention in recent years. ${ }^{62)-65)}$ Proton conductors will play an important role in technology related to hydrogen, which is now recognized as a core material for energy utilization. To realize a carbon-neutral society, which is an urgent global issue, both FC and electrolysis cells using hydrogen are important technologies and we hope that phosphate glass proton conductors fabricated using the APS method will contribute to the development of these technologies.

Acknowledgements The knowledge obtained thus far related to improving proton conductivity, including the development of the APS method to fabricate proton-conductive phosphate glasses described in this paper, was obtained with cooperation from Dr. Hiroshi Kawazoe, Dr. Toshiharu Yamashita, and Dr. Junji Nishii, who have given us excellent advice as collaborators over the years. This work was supported in part by a Grant-in-Aid for Scientific Research (B) (Grant No. 20H02428). This work was partially performed under the Cooperative Research Program of the "Network Joint
Research Center for Materials and Devices" (No. 20194020 , 20204012 and 20214016) and "Dynamic Alliance for Open Innovation Bridging Human, Environment, and Materials."

\section{References}

1) M. Okumura, "Reference Module in Chemistry, Molecular Sciences and Chemical Engineering", Elsevier (2013)

2) T. Murahashi, "Encyclopedia of Electrochemical Power Sources", Elsevier (2009) pp. 564-567.

3) S. M. Haile, D. A. Boysen, C. R. Chisholm and R. B. Merle, Nature, 410, 910-913 (2001).

4) Y. K. Taninouchi, T. Uda, Y. Awakura, A. Ikeda and S. M. Haile, J. Mater. Chem., 17, 3182-3189 (2007).

5) D. A. Boysen, S. M. Haile, H. Liu and R. A. Secco, Chem. Mater., 15, 727-736 (2003).

6) D. A. Boysen, T. Uda, C. R. I. Chisholm and S. M. Haile, Science, 303, 68-70 (2004).

7) K. D. Kreuer, Annu. Rev. Mater. Res., 33, 333-359 (2003).

8) K. D. Kreuer, Solid State Ionics, 97, 1-15 (1997).

9) H. Iwahara, Solid State Ionics, 86-88, 9-15 (1996).

10) K. D. Kreuer, Chem. Mater., 8, 610-641 (1996).

11) H. Zhu, S. Ricote, C. Duan, R. P. O'Hayre, D. S. Tsvetkov and R. J. Kee, J. Electrochem. Soc., 165, F581-F588 (2018).

12) T. Ishiyama, H. Kishimoto, K. Develos-Bagarinao, K. Yamaji, T. Yamaguchi and Y. Fujishiro, Inorg. Chem., 56, 11876-11882 (2017).

13) D. Han, Y. Noda, T. Onishi, N. Hatada, M. Majima and T. Uda, Int. J. Hydrogen Energ., 41, 14897-14908 (2016).

14) E. Fabbri, L. Bi, D. Pergolesi and E. Traversa, $A d v$. Mater., 24, 195-208 (2012).

15) H. Namikawa and Y. Asahara, J. Ceram. Assoc. Japan, 74, 205-212 (1966).

16) Y. Abe, H. Shimakawa and L. L. Hench, J. Non-Cryst. Solids, 51, 357-365 (1982).

17) A. Naruse, Y. Abe and H. Inoue, J. Ceram. Assoc. Japan, 76, 36-50 (1968).

18) Y. Abe and D. E. Clark, J. Mater. Sci. Lett., 9, 244-245 (1990).

19) Y. Abe, H. Hosono, T. Kamae and K. Kawashima, Phosphorus Sulfur, 51, 113-116 (1990).

20) M. Kotama, K. Nakanishi, H. Hosono, Y. Abe and L. L. Hench, J. Electrochem. Soc., 138, 2928-2930 (1991).

21) H. Hosono, Y. Abe and K. Deguchi, J. Non-Cryst. Solids, 142, 103-107 (1992).

22) Y. Abe, H. Hosono, W. Lee and T. Kasuga, Phys. Rev. B, 48, 15621-15625 (1993).

23) Y. Abe, H. Hosono, Y. Ohta and L. L. Hench, Phys. Rev. $B, 38,10166-10169$ (1988).

24) Y. Abe, M. Hayashi, T. Iwamoto, H. Sumi and L. L. Hench, J. Non-Cryst. Solids, 351, $2138-2141$ (2005).

25) H. Sumi, Y. Nakano, Y. Fujishiro and T. Kasuga, Solid State Sci., 45, 5-8 (2015).

26) T. Ishiyama, J. Nishii, T. Yamashita, H. Kawazoe and T. Omata, J. Mater. Chem. A, 2, 3940-3947 (2014).

27) T. Ishiyama, S. Suzuki, J. Nishii, T. Yamashita, H. Kawazoe and T. Omata, J. Electrochem. Soc., 160, E143-E147 (2013).

28) T. Ishiyama, H. Kishimoto, K. Yamaji, T. Yamaguchi, J. Nishii, T. Yamashita, H. Kawazoe and T. Omata, Int. J. 
Hydrogen Energ., 44, 24977-24984 (2019).

29) T. Yamaguchi, S. Tsukuda, T. Ishiyama, J. Nishii, T. Yamashita, H. Kawazoe and T. Omata, J. Mater. Chem. $A, 6,23628-23637$ (2018).

30) A. Chandan, M. Hattenberger, A. El-Kharouf, S. Du, A. Dhir, V. Self, B. G. Pollet, A. Ingram and W. Bujalski, J. Power Sources, 231, 264-278 (2013).

31) T. Nanba, T. Hagiwara and Y. Miura, Adv. Quantum Chem., 42, 187-198 (2003).

32) S. Matsumoto, T. Nanba and Y. Miura, J. Ceram. Soc. Jpn., 106, 415-421 (1998).

33) T. Yamaguchi, Y. Saito, Y. Kuwahara, H. Yamashita, T. Ishiyama, J. Nishii, T. Yamashita, H. Kawazoe and T. Omata, J. Mater. Chem. A, 5, 12385-12392 (2017).

34) R. Brückner, H.-U. Chun, H. Goretzki and M. Sammet, J. Non-Cryst. Solids, 42, 49-60 (1980).

35) R. Sawyer, H. W. Nesbitt and R. A. Secco, J. Non-Cryst. Solids, 358, 290-302 (2012).

36) T. Suzuki, J. Konishi, K. Yamamoto, S. Ogura and K. Fukutani, J. Non-Cryst. Solids, 382, 66-69 (2013).

37) S. Miyasaka, T. Ishiyama, Y. Hayashi and T. Omata, J. Am. Ceram. Soc., 103, 3642-3649 (2020).

38) S. I. Amma, S. H. Kim and C. G. Pantano, J. Am. Ceram. Soc., 99, 128-134 (2016).

39) A. M. Efimov and V. G. Pogareva, J. Non-Cryst. Solids, 275, 189-198 (2000).

40) A. Novak, "Large Molecules", Springer Berlin Heidelberg, Berlin, Heidelberg (1974) pp. 177-216.

41) B. Dereka, Q. Yu, N. H. C. Lewis, W. B. Carpenter, J. M. Bowman and A. Tokmakoff, Science, 371, 160164 (2021).

42) S. Thomas, Angew. Chem. Int. Edit., 41, 48-76 (2002).

43) Y. Abe, G. Li, M. Nogami, T. Kasuga and L. L. Hench, J. Electrochem. Soc., 143, 144-147 (1996).

44) P. McMillan and R. L. Remmele, Am. Mineral., 71, 772-778 (1986).

45) M. Nagao, T. Kamiya, P. Heo, A. Tomita, T. Hibino and M. Sano, J. Electrochem. Soc., 153, A1604-A1609 (2006).

46) G. C. Farrington and J. L. Briant, Mater. Res. Bull., 13, 763-773 (1978).

47) W. A. England, M. G. Cross, A. Hamnett, P. J. Wiseman and J. B. Goodenough, Solid State Ionics, 1, 231-249 (1980).

48) T. Ishiyama, S. Suzuki, J. Nishii, T. Yamashita, H. Kawazoe and T. Omata, Solid State Ionics, 262, 856859 (2014).

49) S. Tsukuda, K. Miyake, T. Yamaguchi, M. Kita, T. Ishiyama, J. Nishii, T. Yamashita, H. Kawazoe and T.
Omata, Inorg. Chem., 56, 13949-13954 (2017).

50) T. Omata, I. Suzuki, A. Sharma, T. Ishiyama, J. Nishii, T. Yamashita and H. Kawazoe, RSC Adv., 11, 30123019 (2021).

51) T. Ishiyama, T. Yamaguchi, J. Nishii, T. Yamashita, H. Kawazoe, N. Kuwata, J. Kawamura and T. Omata, Phys. Chem. Chem. Phys., 17, 13640-13646 (2015).

52) T. Yamaguchi, T. Ishiyama, K. Sakuragi, J. Nishii, T. Yamashita, H. Kawazoe and T. Omata, Solid State Ionics, 275, 62-65 (2015).

53) K. Kawaguchi, T. Yamaguchi, T. Omata, T. Yamashita, H. Kawazoe and J. Nishii, Phys. Chem. Chem. Phys., 17, 22855-22861 (2015).

54) T. Yamaguchi, T. Ishiyama, K. Sakuragi, J. Nishii, T. Yamashita, H. Kawazoe, N. Kuwata, J. Kawamura and T. Omata, Solid State Ionics, 288, 281-285 (2016).

55) T. Yamaguchi, T. Kataoka, S. Tsukuda, T. Ishiyama, J. Nishii, T. Yamashita, H. Kawazoe and T. Omata, Phys. Chem. Chem. Phys., 19, 29669-29675 (2017).

56) T. Kinoshita, A. Miyazaki, K. Kawaguchi, D. Sakai, T. Yamaguchi, T. Omata, T. Ishiyama, M. Fujioka, H. Kaiju and J. Nishii, Appl. Surf. Sci., 428, 718-722 (2018).

57) T. Omata, T. Yamaguchi, S. Tsukuda, T. Ishiyama, J. Nishii, T. Yamashita and H. Kawazoe, Phys. Chem. Chem. Phys., 21, 10744-10749 (2019).

58) A. Miyazaki, T. Kinoshita, T. Tatebayashi, T. Fang, Y. Ren, T. Ishiyama, T. Yamaguchi, T. Omata, M. Fujioka, K. Hideo, G. Zhao and J. Nishii, J. Non-Cryst. Solids, 541, 120064 (2020).

59) T. Ishiyama, T. Yamaguchi, J. Nishii, T. Yamashita, H. Kawazoe and T. Omata, To be published.

60) I. Suzuki, M. Tashiro, T. Yamaguchi, T. Ishiyama, J. Nishii, T. Yamashita, H. Kawazoe and T. Omata, Int. J. Hydrogen Energ., 45, 16690-16697 (2020).

61) T. Omata, A. Sharma, T. Kinoshita, I. Suzuki, T. Ishiyama, S. Kohara, K. Ohara, M. Ono, T. Fang, Y. Ren, M. Fujioka, G. Zhao and J. Nishii, J. Mater. Chem. A, 9, 20595-20606 (2021).

62) M. Makri, A. Buekenhoudt, J. Luyten and C. G. Vayenas, Ionics, 2, 282-288 (1996).

63) I. Kalaitzidou, A. Katsaounis, T. Norby and C. G Vayenas, J. Catal., 331, 98-109 (2015).

64) C. Kokkofitis, M. Ouzounidou, A. Skodra and M. Stoukides, Solid State Ionics, 178, 507-513 (2007).

65) A. Thursfield, S. Brosda, C. Pliangos, T. Schober and C. G. Vayenas, Electrochim. Acta, 48, 3779-3788 (2003). 